\title{
Nonlinear regression model for predicting environmental traffic noise
}

\section{Modelo de regressão não linear para prever o ruído do tráfego ambiental}

\author{
Alana Corsi Mestranda em Engenharia de Produção. Universidade Tecnológica Federal do Paraná (UTFPR) - Brasil. \\ aaacorsi@gmail.com \\ Doutoranda em Engenharia de Produção. Universidade Tecnológica Federal do Paraná (UTFPR) - Brasil. fran- \\ aragao@hotmail.com \\ Franciely Velozo Aragão \\ Daiane Chiroli \\ Doutora em Engenharia de Produção. Universidade Tecnológica Federal do Paraná (UTFPR) - Brasil. \\ dmgenaro@gmail.com \\ Márcia Santos Graduada em Estatística. Universidade Estadual de Maringá (UEM) - Brasil. marcialorena16@hotmail.com \\ Eniuce Souza Doutora em Estatística. Universidade Estadual de Maringá (UEM) - Brasil. eniucemenezes@gmail.com \\ Marcia Samed Doutora em Engenharia de Produção. Universidade Estadual de Maringá (UEM) - Brasil. mmasamed@uem.br \\ Paulo Soares Doutor em Engenharia Civil. Universidade Estadual de Maringá (UEM) - Brasil. paulofsoares@gmail.com
}

\begin{abstract}
Transport is an essential activity for urban life and for the economy, however, bad planning of the city script causes some movement in some places, causing excessive noise levels generated by road traffic. We aim to present a mathematical model that represents the relationship between the equivalent level of sound and vehicle volume quantities using the nonlinear logistic regression model in order to facilitate decision-making in relation to urban planning. We collected the data of sound pressure and vehicle volume for ten days during five hours totaling a collection of 50 hours, with a total of 180 thousand data of sound pressure level. The place of data collection is a highway that passes through the city of Maringá, in Paraná, being an intense traffic highway. The results show the performance of the proposed model were differences between measured and predicted traffic noise levels ranged from $-0.3 \mathrm{~dB}(\mathrm{~A})$ to $+0.3 \mathrm{~dB}(\mathrm{~A})$ and the mean difference was $-0.006 \mathrm{~dB}(\mathrm{~A})$. The proposed road traffic noise forecasting model can be used as a decision support tool in urban planning, considering the same boundary conditions as the road study.
\end{abstract}

Keywords: Sound Equivalent Level. Traffic noise. Mathematical Optimization Model.

\section{RESUMO}

Muitos estudos sobre o impacto ambiental em áreas urbanas estão relacionados ao ruído do tráfego rodoviário. O transporte é uma atividade essencial à vida urbana e à economia, seja ele de pessoas ou bens de consumo, os tipos de veículos para transporte são classificados em veículos leves ou pesados. Entretanto, o mau planejamento da roteirização das cidades ocasiona certa movimentação em demasia em alguns pontos, causando níveis excessivos de ruído gerados pelo tráfego rodoviário. Este estudo tem como objetivo apresentar um modelo matemático que represente a relação entre as grandezas Nível Equivalente Sonoro e Volume Veicular, utilizando o modelo de regressão logística não linear, a fim de facilitar a tomada de decisão em relação ao planejamento urbano. Os dados de pressão sonora e volume veicular foram coletados por dez dias durante cinco horas totalizando uma coleta de 50 horas, com um total de 180 mil dados de nível de pressão sonora e 124.316 veículos. O local de coleta de dados foi uma rodovia que passa pela cidade de Maringá, no Paraná, sendo uma rodovia de tráfego intenso. Os resultados mostram que as diferenças entre os níveis de ruído de tráfego medido e previsto variam de $-0,3 \mathrm{~dB}(\mathrm{~A})$ a $+0,3 \mathrm{~dB}(\mathrm{~A})$ e a diferença média foi de $0,006 \mathrm{~dB}(\mathrm{~A})$. O modelo de previsão de ruído de tráfego rodoviário proposto pode ser utilizado como ferramenta de apoio à decisão no planejamento urbano, levando em consideração as mesmas condições de contorno da rodovia estudada.

Palavras-chave: Nível Equivalente Sonoro. Ruído de Tráfego. Modelo de Otimização Matemática. 


\section{INTRODUCTION}

Ever since the emergence of cities, man has always sought ways to move around and move his goods. With its evolution and with the industrialization, this need is even greater, for the movement of goods and people at substantial distances, while a globalization has strongly increased these flows (Molina and Molina, 2012). This has resulted in problems with the construction of a supply system, as well as problems of congestion and urban mobility (Cattaruzza et al., 2017).

Transportation systems, whether urban or freight, cause damage to health, accidents and pollution, which may be due to the emission of air pollutants, high noise, and contamination of soils and water, in this sense the emission of these harmful agents must be minimized in order to preserve the population at high levels of these pollutants. (Taniguchi et al., 2014). Allied to this, the increasing use of motor vehicles has increased the occurrence of environmental problems, besides the problems of flow in urban roads (Who, 2009; Tadic et al., 2004; Hesse and Rodrigue, 2004; Melo, 2002; Smith, 2015; Goines and Hagler, 2007).

The development of countries is directly related to problems such as congestion, accidents and environmental pollution (Jica, 2007), and together with the lack of planning of cities, problems such as noise production occur (Marques, 2010), which according to Zannin et al. (2003) and Nunes (1999), is one of the most common and troublesome environmental problems that has affected the world population (Suthanaya, 2015). Koç et al. (2016) mentions that such problems can be solved through innovative mechanisms developed between public and private sector partnerships.

From the above, it can be seen that urban logistics is a very important tool, since it consists of a combination of transportation planning and urban environment, contributing to the achievement of economic and environmental objectives (Lidasan, 2001). Urban logistics is defined as the process of optimizing logistics and transport activities by private companies in urban areas, considering traffic, congestion and energy consumption (Taniguchi et al., 1999). Dutra (2014) shows that the movement of goods in urban areas affects urban planning and causes environmental and health problems. Based on the population's awareness in this regard, and the integration between the precepts of urban logistics and the concern with physical infrastructure logistics and road safety, resulted in City logistics (Gwillian, 2012). City Logistics aims to reduce traffic congestion, increase mobility, reduce pollution and noise levels considerably (Ricciardi et al., 2003; YANG et al., 2016).

"Traffic noise is an undesirable sound", the noise level, related to urban problems and noise pollution generated by traffic, is one of the major problems of the lack of urban planning, responsible for reducing the quality of life of the population, and to cause degradation of acoustic comfort in urban areas. (Ow and Ghosh, 2017; Maijala et al., 2012; Debnath and Singh, 2018; Morillas et al., 2002, Lee, 2007). In this sense, it can be affirmed that considering the problems caused by the movement of goods and people in urban areas, evaluating the problems and the actions to control the adverse effects are becoming a concern for the community, evidenced by the great number of laws and regulations that limiting noise (Mansouri et al., 2006). Ramírez and Domínguez (2013) report that studies on traffic noise have been growing considerably, especially in countries where the maximum levels of tolerance established by regulations are exceeded, notably Spain, India, China and Brazil.

According to the World Health Organization (Who, 2009), excess noise in urban areas causes problems in the health and well-being of the inhabitants, generating diseases such as stress and discomfort for noise up to $55 \mathrm{~dB}$, and from $65 \mathrm{~dB}$ promotes degrative stress, increases the risk of heart attack; stroke; infections, among others.

In a study carried out by Aragão (2016), the Brazilian city of Maringá - Paraná, is governed by law number 218/98, which provides limits of tolerance of noise levels for each area of urban zoning. Also, the Brazilian Association of Technical Standards (ABNT) defines the limits of acceptable noise levels for each type of area, according to the period of the day, in decibels, as described in NBR 10151:2000, which describes that in mixed areas, predominantly residence, the acceptable noise level in daytime is $55 \mathrm{~dB}$ and in night time is 50 $\mathrm{dB}$. 
In addition, according to research by Calixto et al. (2001), the noise that most annoys the population is the traffic generated by vehicles. Therefore, according to Guarnaccia (2013), the need to measure traffic noise in urban areas is evident, and necessary for urban planning (Garg and Maji, 2014).

For Suthanaya (2015); Giraldo and Fernandez (2011) and Guarnaccia (2013), the development of models and methodologies that monitor the environmental noise is necessary to know the critical points, to map sensitive areas and to apply the measures of reduction of the sound levels. Kumar et al. (2014) used an artificial neural network model to predict traffic noise, Li et al. (2016) used the Monte Carlo simulation to develop a statistical model of probability to predict traffic noise, and all studies take into account the contour characteristics of each location using known mathematical techniques to predict noise from traffic.

The development and use of mathematical modeling to monitor the Sound Pressure Level (SPL) of vehicle traffic represents a gain for the study of the noise pollution problem and for urban planning of existing and under way roadways (Calixto et al., 2001). Silva and Mendes (2012) elaborated an index of environmental quality for cities, which considers indicators of air pollution and noise pollution, in its application, it was efficient in the combination of only one technique that could help urban planning in decisions strategies. Cai et al. (2015) carried out a study on road traffic noise mapping through the creation of a regional noise calculation algorithm for the Guangzhou region of China. Maijala et al. (2012) proposed a concept of SPL monitoring by means of an algorithm, which classifies the sound sources by means of a wire sensor.

According to Regazzi and Silva (2004), the study between a dependent variable and one or more independent variables can be performed using the nonlinear regression model, and also, according to Mazucheli et al. (2011) nonlinear regression models are formulated based on the theoretical knowledge inherent to the object of study, being the method used in this article.

Thus, we aim to develop a mathematical model, which represents the relationship between vehicular volume and the sound equivalent level, allowing control and support to the application of control measures of the pathway under study, also, to compare noise levels measured at the site with the limits acceptable by NBR 10151: 2000 and by the levels acceptable by the World Health Organization, classifying the acoustic quality of this area. For this, we collected the data on a highway in Maringá, Paraná, characterized by intense traffic of light and heavy vehicles. In addition, the highway passes through the middle of the city, in mixed areas, predominantly residential.

\section{MATERIALS AND METHODS}

In this section, we described the methodological procedures of the research, starting from the characterization of the studied area, and later the method of collection and processing data, as follows.

\subsection{Characterization of The Studied Area}

The area of evaluation of this work is situated in the city of Maringá, located in the northwest of Paraná - Brazil, being the third largest city of the State, positioned in the geographical coordinates: Latitude $23 \circ 25$ '31' 'S and Longitude $51^{\circ} 56^{\prime} 19^{\prime}$ 'W, cut by the Tropic of Capricorn, having an altitude of 555 meters.

The acoustic monitoring points are located at Colombo Avenue (Federal Highway BR-376), which is characterized as an Urban Crossing, being described as an intense traffic and long distance road composed of heavy vehicles, light vehicles, motorcycles and bicycles. BR-376 is a Diagonal Highway connecting the cities of Garuva / SC and Dourados / MS, crossing the State of Paraná, with an extension of approximately 958,3 Km.

The highway under study has intersections with streets of local traffic and viaducts to access the collecting traffic ways. The track section is variable, depending on the presence of central beds, however, the width of the tracks is constant, being $3.1 \mathrm{~m}$ each lane. As the highway is inserted in the city, the maximum speed allowed is $60 \mathrm{~km} \mathrm{~h} \mathrm{-1.} \mathrm{In} \mathrm{addition,} \mathrm{the} \mathrm{sites} \mathrm{of} \mathrm{the} \mathrm{collection} \mathrm{point} \mathrm{are} \mathrm{characterized} \mathrm{by} \mathrm{having,} \mathrm{apart}$ from intense traffic, trade spots and is predominantly residential. 


\subsection{Method of collecting and processing Data}

Firstly, we performed the acoustic monitoring in the study sites where the Sound Pressure Levels were captured, according to equation 1 , and the volume of vehicles passing through the site. In order to do it, a portable sonometer, model DL4200, of ICEL, with $1.4 \mathrm{~dB}$ precision, in addition to a Sony camcorder, model DCR-SX21, was used for the purpose of recording the flow of vehicles during the monitoring period.

The SPL is all acoustic energy emitted by a particular source. In sound monitoring the SPL varies during a given time interval $(T)$, where the average one represents the Equivalent Sound Pressure Level (Leq) reports Bistafa, (2011). The SPL is defined by ISO 1996/1 (1987), having as unit the decibels (dB), according to equation 1.

$$
S P L=10 \log \left[\left(\frac{P}{P_{0}}\right)^{2}\right]
$$

Where P: Sound pressure in pascal; $P_{0}$ : Reference Sound Pressure.

Leq is also defined according to ISO 1996/1 (1987), having as unit the dB, according to equation 2.

$$
L e q=10 \log \left[\frac{1}{T} \times \sum_{i=1}^{n} t_{i} \times 10^{\frac{L i}{10}}\right]
$$

Where T: Total time in hours; Li: Sound Intensity Level in $\mathrm{dB}$; Ti: Partial time in hours.

The data samples, vehicle volume and SPL, were collected on different days of the week and in the afternoon period with a duration of five hours, thus, being in accordance with ISO 11819-1, Acoustics Measurement of the influence of road surfaces on traffic noise - Part 1: Statistical Pass-By method, which provides that the monitoring for the calculation of Leq can vary between 1 and 4 hours of measurement during the day in the rush hour.

Regarding the meteorological conditions, the monitoring was carried out on days with conditions considered normal, with clear skies, without rain or any meteorological interference that could compromise the reliability of the data.

After tabulating the vehicle volume and sound pressure data, a regression analysis was performed, which consisted of investigating and modeling the dependence relation between a random variable and the possible explanatory causes of its variability, represented by one or more predictor variables. In this study, the noise level was considered as the random variable $Y$ and the number of vehicles that as the predictor variable $X$. Firstly, we performed the study of the relation between the variables $X$ and $Y$, looking for a mathematical function of $X$ that explains $Y$. However, since this relation is not perfect, for the observed values would not be perfectly situated on a function that related $X$ and $Y$, the type of function adopted was suggested by empirical evidence, that is, based on the observations of the variables. One can evaluate the behavior of the relation approaching a line or any other curve. After the study of the relation between the variables, we tested the regression models that represent the behavior of these variables, in order to find the model that best represents the parameters. To choose the best model, we used the criterion of the lowest AIC (Akaike Criterion Information). To apply such models to the data, we used the gcFitModel command belonging to the $\mathrm{R}$ software grofit package.

\section{RESULTS AND DISCUSSION}

After the collection stage, we organized the data on the amount of light and heavy vehicles per hour traveling in the studied road, and the value of Sound Equivalent Level (Leq), calculated from the monitored 
SPL, in Table 1. A collection of information on the noise level caused by light and heavy vehicular traffic on Colombo Avenue occurred during ten days, with five hours a day and on different days of the week, excluding holidays or days that could cause changes in normal traffic conditions.

\begin{tabular}{|c|c|c|c|c|c|}
\hline \multirow[t]{2}{*}{ Data } & \multicolumn{2}{|c|}{ Period } & \multirow{2}{*}{$\begin{array}{l}\text { Light Vehicle } \\
\text { Volume (Light } \\
\text { Vehicle / h) }\end{array}$} & \multirow{2}{*}{$\begin{array}{l}\text { Heavy Vehicle } \\
\text { Volume (Heavy } \\
\text { Vehicle / h) }\end{array}$} & \multirow{2}{*}{$\begin{array}{l}\text { Leq measured } \\
\text { period }(\mathrm{dBA})\end{array}$} \\
\hline & Beginning & End & & & \\
\hline 1 & 13:00:00 & 14:00:00 & 2609 & 249 & 74,1 \\
\hline 2 & $14: 00: 00$ & 15:00:00 & 2658 & 291 & 74,3 \\
\hline 3 & 15:00:00 & 16:00:00 & 2981 & 299 & 74,5 \\
\hline 4 & 16:00:00 & 17:00:00 & 2271 & 237 & 74,0 \\
\hline 5 & 17:00:00 & 18:00:00 & 2140 & 220 & 73,9 \\
\hline 6 & 13:00:00 & 14:00:00 & 2306 & 287 & 74,3 \\
\hline 7 & 14:00:00 & 15:00:00 & 2445 & 253 & 74,3 \\
\hline 8 & 15:00:00 & 16:00:00 & 2308 & 238 & 74,1 \\
\hline 9 & 16:00:00 & 17:00:00 & 2240 & 229 & 74,1 \\
\hline 10 & $17: 00: 00$ & 18:00:00 & 2357 & 273 & 74,2 \\
\hline 11 & 13:00:00 & 14:00:00 & 2948 & 269 & 74,5 \\
\hline 12 & 14:00:00 & 15:00:00 & 2514 & 272 & 74,1 \\
\hline 13 & 15:00:00 & 16:00:00 & 2148 & 252 & 74,0 \\
\hline 14 & $16: 00: 00$ & $17: 00: 00$ & 2105 & 207 & 73,6 \\
\hline 15 & 17:00:00 & 18:00:00 & 1878 & 200 & 73,3 \\
\hline 16 & 13:00:00 & 14:00:00 & 3228 & 332 & 74,6 \\
\hline 17 & $14: 00: 00$ & 15:00:00 & 2431 & 230 & 74,1 \\
\hline 18 & 15:00:00 & 16:00:00 & 1960 & 201 & 73,8 \\
\hline 19 & 16:00:00 & 17:00:00 & 2532 & 245 & 74,2 \\
\hline 20 & $17: 00: 00$ & 18:00:00 & 1938 & 193 & 73,5 \\
\hline 21 & 13:00:00 & 14:00:00 & 2072 & 254 & 74,1 \\
\hline 22 & 14:00:00 & 15:00:00 & 2218 & 236 & 74,2 \\
\hline 23 & $15: 00: 00$ & 16:00:00 & 2630 & 267 & 74,3 \\
\hline 24 & 16:00:00 & 17:00:00 & 2807 & 257 & 74,4 \\
\hline 25 & $17: 00: 00$ & 18:00:00 & 2367 & 250 & 74,3 \\
\hline 26 & 13:00:00 & 14:00:00 & 2174 & 224 & 74,2 \\
\hline 27 & 14:00:00 & 15:00:00 & 2784 & 224 & 74,3 \\
\hline 28 & 15:00:00 & 16:00:00 & 3319 & 338 & 74,6 \\
\hline 29 & $16: 00: 00$ & $17: 00: 00$ & 2506 & 229 & 74,1 \\
\hline 30 & 17:00:00 & 18:00:00 & 1924 & 199 & 73,7 \\
\hline 31 & 13:00:00 & 14:00:00 & 2110 & 229 & 74,2 \\
\hline 32 & $14: 00: 00$ & 15:00:00 & 2028 & 223 & 74,0 \\
\hline 33 & 15:00:00 & 16:00:00 & 2462 & 273 & 74,4 \\
\hline 34 & $16: 00: 00$ & 17:00:00 & 1446 & 142 & 72,5 \\
\hline 35 & $17: 00: 00$ & 18:00:00 & 1381 & 155 & 72,6 \\
\hline 36 & 13:00:00 & 14:00:00 & 2658 & 231 & 74,2 \\
\hline 37 & $14: 00: 00$ & 15:00:00 & 2158 & 255 & 74,1 \\
\hline 38 & $15: 00: 00$ & 16:00:00 & 2094 & 209 & 73,8 \\
\hline 39 & $16: 00: 00$ & 17:00:00 & 2141 & 193 & 73,8 \\
\hline
\end{tabular}




\begin{tabular}{llllll}
\hline $\mathbf{4 0}$ & $17: 00: 00$ & $18: 00: 00$ & 1621 & 161 & 72,9 \\
\hline $\mathbf{4 1}$ & $13: 00: 00$ & $14: 00: 00$ & 2198 & 246 & 74,2 \\
\hline $\mathbf{4 2}$ & $14: 00: 00$ & $15: 00: 00$ & 2050 & 229 & 74,1 \\
\hline $\mathbf{4 3}$ & $15: 00: 00$ & $16: 00: 00$ & 2038 & 206 & 73,8 \\
\hline $\mathbf{4 4}$ & $16: 00: 00$ & $17: 00: 00$ & 2053 & 204 & 73,8 \\
\hline $\mathbf{4 5}$ & $17: 00: 00$ & $18: 00: 00$ & 1499 & 166 & 72,9 \\
\hline $\mathbf{4 6}$ & $13: 00: 00$ & $14: 00: 00$ & 2132 & 211 & 74,0 \\
\hline $\mathbf{4 7}$ & $14: 00: 00$ & $15: 00: 00$ & 1845 & 200 & 73,4 \\
\hline $\mathbf{4 8}$ & $15: 00: 00$ & $16: 00: 00$ & 2159 & 279 & 73,7 \\
\hline $\mathbf{4 9}$ & $16: 00: 00$ & $17: 00: 00$ & 2001 & 221 & 73,2 \\
\hline $\mathbf{5 0}$ & $17: 00: 00$ & $18: 00: 00$ & 1768 & 188 & \\
\hline \multicolumn{5}{c}{ Table 1: Relation between vehicle volume and Leq } \\
\end{tabular}

Considering that, in this study, the noise level is represented by the random variable $Y$ and the number of vehicles that traveled through Colombo Avenue as the predictor variable $X$, the data pairs $(X, Y)$ were plotted in the scatter diagram shown in Figure 1.

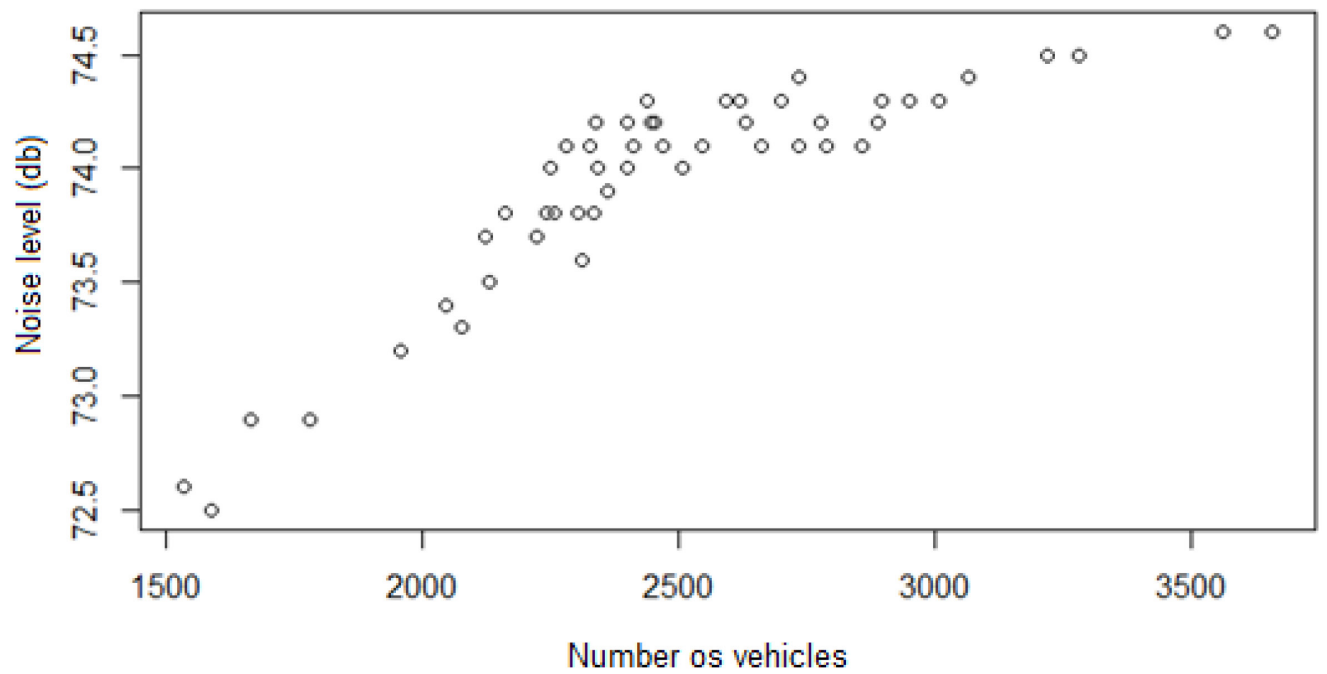

Figure 1: Graphic relation between vehicle volume and sound level Source: The authors (2018)

From Figure 1, we verify that the relation between the variables $X$ and $Y$ does not resemble a line, suggesting that the mathematical function of $X$ that explains $Y$ must actually be nonlinear. In order to confirm this fact, a linear model was fitted to the data $(A I C=2.98)$, but the residuals showed non-random behavior, indicating the presence of patterns in the data not modeled by the adjusted linear curve.

The nonlinear function suitable to describe the relation between the variables X: "number of vehicles" and $Y$ : "noise level" was the Logistics curve, which has three parameters $A, \mu$ and $\lambda$, being defined by equation 3.

$$
f(X)=\frac{A}{1+e^{\left[\frac{4 \mu}{A}(\lambda-X)+2\right]}}
$$


Where: $\mu$ is the maximum slope and $A$ is the horizontal asymptote representing the maximum noise. In many nonlinear models, the parameters are characteristic points of the function and, not rarely, some parameters in the model do not have direct interpretation, such as the $\lambda$ in the logistic curve, are necessary to guarantee flexibility to the model.

The estimates of the parameters $A, \mu$ and $\lambda$ of the Logistics curve and their respective standard errors for the sample of vehicles collected in this study are represented in Table 2.

\begin{tabular}{c|c|c}
\hline Parameter & Estimate & Standard error \\
\hline$\mu$ & $\hat{\mu}=0.025$ & $\hat{\sigma}_{\hat{\mu}}=0.003$ \\
\hline$\lambda$ & $\hat{\lambda}=-2464.138$ & $\hat{\sigma}_{\hat{\lambda}}=474.207$ \\
\hline $\mathrm{A}$ & $\hat{A}=74.705$ & $\hat{\sigma}_{\hat{A}}=0.109$ \\
\hline
\end{tabular}

Table 2: Estimates and standard error of the logistic curve parameters

Souce: The authors (2018)

Also, the AIC was -45.18 while in the linear model it was 2.98 . Besides that, the Confidence Intervals (Cl) for the parameter estimates, with $95 \%$ reliability, were calculated to indicate the significance of the parameters. The results obtained were expressed in Table 3.

\begin{tabular}{c|c|c}
\hline \multirow{2}{*}{ Estimator } & \multicolumn{2}{|c}{ IC (95\%) } \\
\cline { 2 - 3 } & Inferior limit & $\begin{array}{c}\text { Superior } \\
\text { limit }\end{array}$ \\
\hline$\hat{\mu}$ & 0.019 & 0.0314 \\
\hline$\hat{\lambda}$ & -3393.583 & -1534.693 \\
\hline$\hat{A}$ & 74.491 & 74.920 \\
\hline
\end{tabular}

Table 3: 95\% Confidence Intervals for Estimates

Souce: The authors (2018)

Therefore, the nonlinear regression model adjusted to the data and describing the relationship between the variables $\mathrm{X}$ : "number of vehicles", light or heavy, and $\mathrm{Y}$ : "noise level" is the logistic model given by equation 4

$$
Y=\frac{74.7052}{1+e^{\left[\frac{4(0.0255)}{74.7052}(-2464.138-X)+2\right]}}+\epsilon
$$

From equation 3, and from the data collected in Table 1, the graph that shows the relation between the variables $X$ and $Y$ described by the adjusted logistic model, in accordance with Figure 2, was drawn in red.

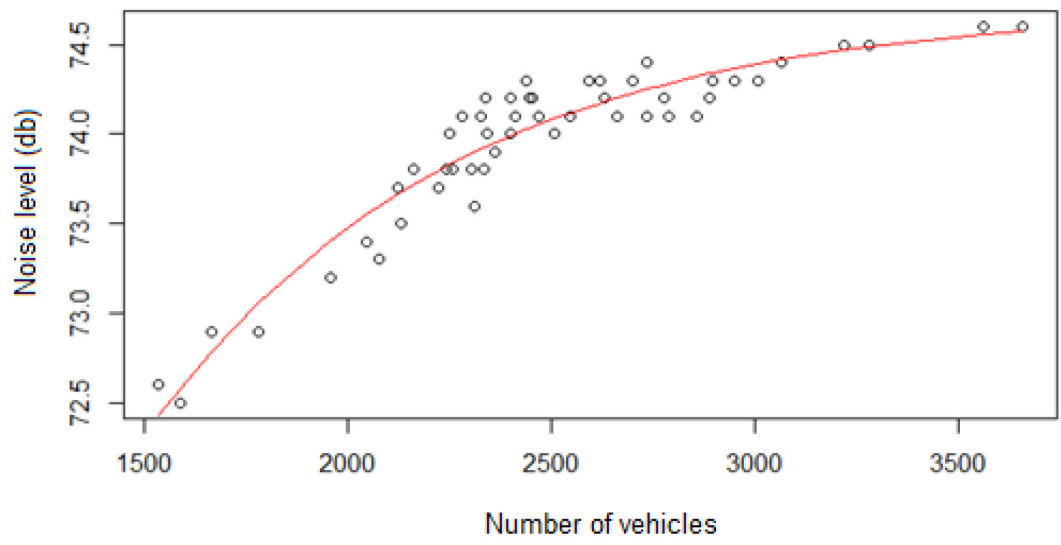


Figure 2: Graphic of the adjusted logistic regression model (in red) describing the relation between the variables $X$ and $Y$

Source: The authors (2018)

It is noted in Figure 2 that the model seems to fit the data well. However, when adopting a regression model, some assumptions are assumed. By performing a residual analysis of the adjusted logistic model, we observed that the assumed assumptions regarding the random error were verified, as shown in the graphs of Figure 3.

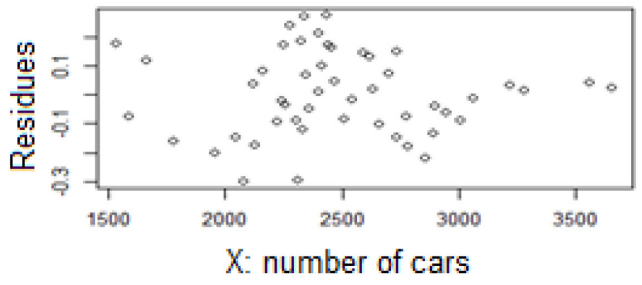

Histogram of the residues

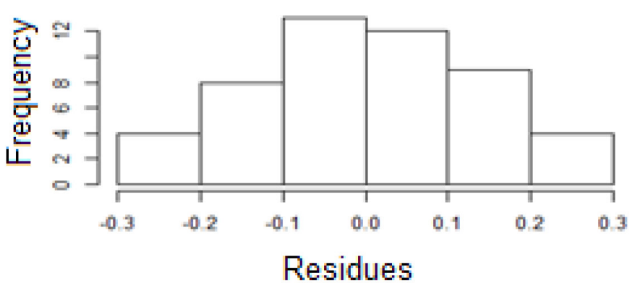

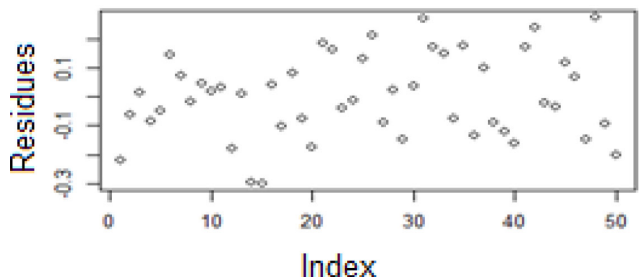

QQ-plot: quantile-quantile graphic

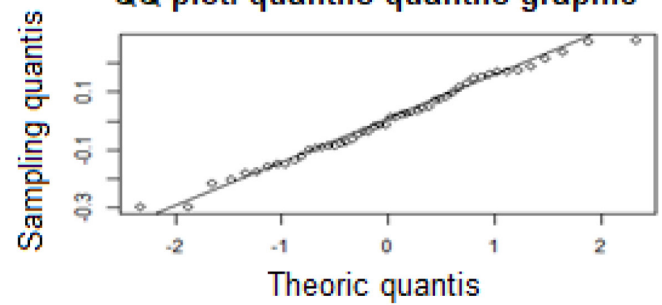

Figure 3: Residual analysis

Source: The authors (2018)

By the histogram and qq-plot presented in Figure 3, it is verified that the errors present normal distribution. Although not presented, correlograms and hypothesis tests that corroborated with the normality (Shapiro-Wilk) and the errors independency, that is absence of autocorrelation, were also verified.

Thus, from the tests of equation three, it was possible to conclude that the logistic model is valid to describe the variables under study.

From the nonlinear regression equation, the Leq was calculated, using equation 3, according to Table 4 , in order to demonstrate the dispersion between the measured and calculated data.

\begin{tabular}{ccccc}
\hline Data & $\begin{array}{c}\mathrm{X} \\
\text { (number } \\
\text { of } \\
\text { vehicles) }\end{array}$ & $\begin{array}{c}\text { Leq } \\
\text { measure } \\
\text { period } \\
(\mathrm{dBA})\end{array}$ & $\begin{array}{c}\text { Leq } \\
\text { calculated } \\
\text { period } \\
(\mathrm{dBA})\end{array}$ & $\begin{array}{c}\text { Differences } \\
\mathrm{dB}(\mathrm{A})\end{array}$ \\
\hline $\mathbf{1}$ & 2858 & 74,1 & 74,3 & $-0,2$ \\
\hline $\mathbf{2}$ & 2949 & 74,3 & 74,4 & $-0,1$ \\
\hline $\mathbf{3}$ & 3280 & 74,5 & 74,5 & 0 \\
\hline $\mathbf{4}$ & 2508 & 74 & 74,1 & $-0,1$ \\
\hline $\mathbf{5}$ & 2360 & 73,9 & 74 & $-0,1$ \\
\hline $\mathbf{6}$ & 2593 & 74,3 & 74,2 & 0,1 \\
\hline $\mathbf{7}$ & 2698 & 74,3 & 74,2 & 0,1 \\
\hline $\mathbf{8}$ & 2546 & 74,1 & 74,1 & 0 \\
\hline $\mathbf{9}$ & 2469 & 74,1 & 74,1 & 0 \\
\hline
\end{tabular}




\begin{tabular}{|c|c|c|c|c|}
\hline 10 & 2630 & 74,2 & 74,2 & 0 \\
\hline 11 & 3217 & 74,5 & 74,5 & 0 \\
\hline 12 & 2786 & 74,1 & 74,3 & $-0,2$ \\
\hline 13 & 2400 & 74 & 74 & 0 \\
\hline 14 & 2312 & 73,6 & 73,9 & $-0,3$ \\
\hline 15 & 2078 & 73,3 & 73,6 & $-0,3$ \\
\hline 16 & 3560 & 74,6 & 74,6 & 0 \\
\hline 17 & 2661 & 74,1 & 74,2 & $-0,1$ \\
\hline 18 & 2161 & 73,8 & 73,7 & 0,1 \\
\hline 19 & 2777 & 74,2 & 74,3 & $-0,1$ \\
\hline 20 & 2131 & 73,5 & 73,7 & $-0,2$ \\
\hline 21 & 2326 & 74,1 & 73,9 & 0,2 \\
\hline 22 & 2454 & 74,2 & 74 & 0,2 \\
\hline 23 & 2897 & 74,3 & 74,3 & 0 \\
\hline 24 & 3064 & 74,4 & 74,4 & 0 \\
\hline 25 & 2617 & 74,3 & 74,2 & 0,1 \\
\hline 26 & 2398 & 74,2 & 74 & 0,2 \\
\hline 27 & 3008 & 74,3 & 74,4 & $-0,1$ \\
\hline 28 & 3657 & 74,6 & 74,6 & 0 \\
\hline 29 & 2735 & 74,1 & 74,3 & $-0,2$ \\
\hline 30 & 2123 & 73,7 & 73,7 & 0 \\
\hline 31 & 2339 & 74,2 & 73,9 & 0,3 \\
\hline 32 & 2251 & 74 & 73,8 & 0,2 \\
\hline 33 & 2735 & 74,4 & 74,3 & 0,1 \\
\hline 34 & 1588 & 72,5 & 72,6 & $-0,1$ \\
\hline 35 & 1536 & 72,6 & 72,4 & 0,2 \\
\hline 36 & 2889 & 74,2 & 74,3 & $-0,1$ \\
\hline 37 & 2413 & 74,1 & 74 & 0,1 \\
\hline 38 & 2303 & 73,8 & 73,9 & $-0,1$ \\
\hline 39 & 2334 & 73,8 & 73,9 & $-0,1$ \\
\hline 40 & 1782 & 72,9 & 73,1 & $-0,2$ \\
\hline 41 & 2444 & 74,2 & 74 & 0,2 \\
\hline 42 & 2279 & 74,1 & 73,9 & 0,2 \\
\hline 43 & 2244 & 73,8 & 73,8 & 0 \\
\hline 44 & 2257 & 73,8 & 73,8 & 0 \\
\hline 45 & 1665 & 72,9 & 72,8 & 0,1 \\
\hline 46 & 2343 & 74 & 73,9 & 0,1 \\
\hline 47 & 2045 & 73,4 & 73,6 & $-0,2$ \\
\hline 48 & 2438 & 74,3 & 74 & 0,3 \\
\hline 49 & 2222 & 73,7 & 73,8 & $-0,1$ \\
\hline 50 & 1956 & 73,2 & 73,4 & $-0,2$ \\
\hline
\end{tabular}


It can be seen that the differences between measured and predicted traffic noise levels ranged from $-0,3 d B(A)$ to $+0,3 d B(A)$ and the mean difference was $-0,006 d B(A)$.

Considering the regulatory norm that guides the evaluation of noise in inhabited areas, with the purpose of promoting comfort to the community, we established the limits of noise level, considering the type of environment in which the measurements were accomplished, represented by the value of the evaluation criterion level (NCA).

Considering the environment to which the measurements were made as a mixed area, predominantly residential, and, that the measurements were carried out during the daytime period, it is assumed that the limits pre-established is $55 \mathrm{dBA}$. Thus, from the measured and calculated Leq values, and the limit established by norm for a given region, it was possible to carry out the data scatter, comparing it with the Leq limit, according to Figure 4.

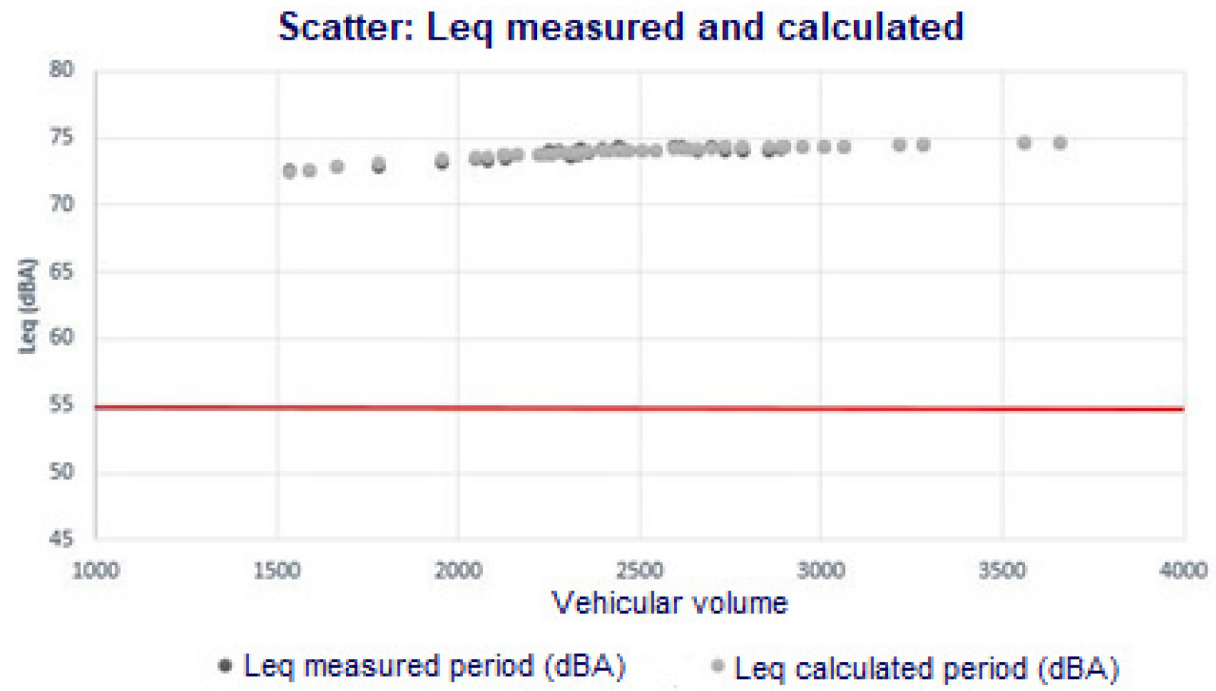

Figure 4: Scatter between measured and calculated Leq

Source: The authors (2018)

Therefore, from the graphic of scatter of SPL, measured and calculated, it was possible to analyze that the limit imposed by NBR 10151: 2000 is not being fulfilled, directly affecting the quality of life of the population in the area. Besides that, it was possible to conclude that the equation 3, Logistic Model, allows to perform the calculations of the noise level of the place under study, in a reliable and representative form. The suggested model allows to perform the noise level calculations in cities similar to the study, having the same contour conditions of the analyzed pathway.

It should be noted that the volume of traffic flow plays a significant role in the emission of traffic noise, which reflects the environmental impact on public health. The present study showed that the use of the environmental noise prediction model could be used in urban planning in order to reduce traffic noise levels and minimize public health problems around busy highways.

\section{FINAL CONSIDERATIONS}

Globalization and urbanization in centers cause great flows of movement of cargoes and people. Urban logistics has been applied in order to bring greater harmony in the transport sector and urban planning, contributing to the fulfillment of the economic objectives and environmental laws, enabling an improvement in the life quality of the population. The evidence available on the impacts of vehicular pollution on human health is overwhelming and sufficient for many years to demonstrate the importance of controlling emissions from mobile sources. 
Thus, we studied the relation between vehicle volume and sound level at Colombo Avenue, which crosses the city of Maringá, in order to find a function capable of representing the relation between these variables at the location described. Hence, with the regression model found, we measure the noise level from a vehicle count in the area, facilitating the monitoring and supporting the decision-making and better control of the variables. Since, as said, they influence the quality of life of the surrounding population and are responsible for a portion of environmental pollution and degradation of public roads.

The results showed that the sound levels in the place exceeded the reference value, established by the Brazilian standard NBR 10151: 2000, thus requiring actions that reduce the vehicle volume and noise level. In addition, the results showed that the nonlinear regression model, Logistic Model, allows to perform the calculations of the noise level of the place under study, in a reliable and representative form, and can be used in other areas similar to the study, having the same contour conditions of the analyzed road.

\section{REFERENCES}

Aragão, F. V.; Soares, P. F.; Chiroli, D. M. G.; Zola, F. C.; Samed, M. M. A. (2016). Mathematical optimization model for Equivalent Noise Level. Rev. Téc. Ing. Univ. Zulia. Vol. 39, № 6, 1 - 9.

Bistafa, S. R. (2011). Acústica aplicada ao controle de ruído. Second edition, São Paulo: Edgard Blücher.

Cai, M. et al. (2015). Road traffic noise mapping in Guangzhou using GIS and GPS. Applied Acoustics, 87, p. 94102.

Debnath, A.; Singh, P. K. (2018). Environmental traffic noise modelling of Dhanbad township area-A mathematical based approach. Applied Acoustics, 129, p. 161-172.

Giraldo, W.; Fernández, A. (2011). Intervalo unitario de tiempo de medición para ruido ambiental. Revista Ingenierías Universidad de Medellín, 10(18), p. 61-68.

Guarnaccia, C. (2013). Advanced tools for traffic noise modelling and prediction. WSEAS Transaction on Systems, 12(2), 121-130.

Hesse, M.; Rodrigue, JP. (2004). The transport geography of logistics and freight distribution. Journal of Transport Geography, 12(3), 171-184.

Koç, Ç. et al. (2016). The impact of depot location, fleet composition and routing on emissions in city logistics. Transportation Research Part B: Methodological, v. 84, p. 81-102.

Kumar, P.; Nigam, S. P.; Kumar, N. (2014). Vehicular traffic noise modeling using artificial neural network approach. Transportation Research Part C: Emerging Technologies, v. 40, p. 111-122.

Maijala, P. et al. (2012). Environmental noise monitoring using source classification in sensors. Applied Acoustics, 129, p. 258-267.

Mansouri, N. A., PourMahabadian, M., Ghasemkhani, M. (2006). Road Traffic Noise in Downtown Area of Tehran. Iranian Journal Of Environmental Health Science And Engineering, 3(4), 261-266.

Molina, M. J.; Molina, L. T. (2012). Megacities and Atm ospheric Pollution. Journal of the Air \& Waste Management Association, 54, 644-680.

Ow, L. F.; Ghosh, S. (2017). Urban cities and road traffic noise: Reduction through vegetation. Applied Acoustics, 120, p. 15-20.

Ramírez, A.; Domínguez, E. (2013). Modeling urban traffic noise with stochastic and deterministic traffic models. Applied Acoustics, 74(4), p. 614-621.

Ricciardi, N., Crainic, T. G.; Storchi, G. (2003). Planning models for city logistics Operations. Journées de I'Optimization: Optimizations Days. Séance TA6 - Logistique II/ Logistics II. 
Silva, L. T.; Mendes, J. F. G. (2012). City noise-air: an environmental quality index for cities. Sustainable Cities and Society, 4, p. 1-11.

Smith, M. E. (2015). Moving Towards a Greener Future: An Investigation of How Transit-Oriented Development Has the Potential to Redefine Cities Around Sustainability. Scripps Senior Theses. 534.

Suthanaya, P. A. (2015). Modelling road traffic noise for collector road (case study of Denpasar City). Science Direct. The 5th International Conference of Euro Asia Civil Engineering Forum (EACEF-5). 125, 467-473.

Taniguchi, E.; Thompson, R. G.; Yamada, T. (1999). Modeling cities logistics. City Logistics l, p. 3-37.

Taniguchi, E.; Thompson, R. G.; Yamada, T. (2014). Recent trends and innovations in modelling city logistics. Procedia-Social and Behavioral Sciences, 125, p. 4-14.

World Health Organization (WHO) (2009). Night noise guidelines for Europe. Copenhagen: WHO.

Yang, J.; Guo, J.; Ma, S. (2016). Low-carbon city logistics distribution network design with resource deployment. Journal of Cleaner Production, 119, 223-228.

Zannin, P. H. T., Calixto, A., Diniz, F. B., Ferreira, J. A.C. (2003). A survey of urban noise annoyance in a large Brazilian city: the importance of a subjective analysis in conjunction with an objective analysis. Environ. Impact. Assessment. Rev., 23, 245-255. 